\title{
Assessment of Nursing staff's Knowledge and Practice regarding Care of Premature Babies in Mosul Teaching Hospitals
}

\author{
Qusay Norry Mohammed *
}

Bakir Faris Alsawaf **

\section{ABSTRACT}

Background and aim: Premature is a live born infant delivered before 37 weeks from the first day of last menstrual period .It accounts for the largest number of admissions to neonatal intensive care unit (NICU) . Premature infants can develop a range of problems because their organs are not mature enough. The proper nursing care of premature baby should be established by good nursing performances . The purpose of this study is to assess of nursing staff knowledge and practice regarding care of premature babies in Mosul Hospitals in the (Premature babies units).

Materials and method: A descriptive design carried throughout the period $2^{\text {nd }}$ of December 2013 to March $2^{\text {nd }} 2014$ employing quantitative research methods to attain the results. The sample of the study was a non-probability purposive sampling which included all the nurses working in the premature units in these four Hospitals the sample consisted of (60) nurses (females).The data were analyzed using the statistical package for social science (SPSS) program version 17 throughout the application of descriptive statistic (frequency, mean, standard deviation and percentage) and inferential statistics (t-test and ANOVA-one way test).

Results: The findings of the study the Having diploma degree, being 40-49 years old, and more clinical experience Nurses in the Premature babies units increase neonatal nursing knowledge and practices.

Conclusions: There are significant differences between knowledge and practice of nursing staff about nursing care for premature babies with regard to age, level of education, and duration of work. Having diploma degree, being 40-49 years old, and more clinical experience in premature babies units increase neonatal nursing knowledge and practices. Recommendation: The study recommends preparing, Nurses should update their knowledge and practice through training courses and training programs for nursing care for premature baby in order to improve their skills and performing statistics by ministry of health of Iraq on the number of premature births in the country in order to reduce this phenomenon and finding appropriate solutions to the problems.

Keywords: Nurses, Knowledge, Practice, Premature Babies.

\section{INTRODUCTION}

Preterm birth (PTB) is a worldwide health problem and remains the leading cause of prenatal morbidity and mortality. In industrialized countries, preterm delivery is responsible for $70 \%$ of mortality and $75 \%$ of morbidity cases during the neonatal period, contributing to significant long-term neurodevelopment problems, pulmonary dysfunction, and visual impairment (Iacovidou et. al., 2010) .Prematurity is a major health problem, it is a leading cause of infant mortality. Premature birth is a worldwide phenomenon. It has been estimated that approximately 24 million low birth weight infants are born every year. (World Health Organization, 2007). Furthermore, preterm baby survival and care round the world is bleak and each year 15 million babies are born preterm and their survival chances vary dramatically around the world. (Blencowe et. al., 2012).Prematurity is a major direct cause of an estimated $28 \%$ of neonatal deaths. Low birth weight (LBW), caused by either prematurity or intrauterine growth restriction, directly or indirectly contributes to 60 to $80 \%$ of neonatal mortality (Lawn et. al., 2005).

Nursing care for premature babies during their first hours of birth, often determines their survival possibilities, especially for premature babies or those with low birth weight in relation to the gestation period. These babies need warmth, physical care, careful feeding, and protection against infection, along with intensive care during the gestation period. Premature babies have to struggle to grow properly outside the uterus; their premature birth before the fulldevelopment of body organs or being retarded because of the environment of the uterus makes them vulnerable. Consequently, the nurse is a key factor in helping them thrive and survive by increasing their survival and growth possibilities and preventing the development of external complications which increase the chances of vulnerability (AL-Maini, 2003).

\footnotetext{
* M. Sc Candidate / Ninavah Health Diroctrate .

** Professor / College of Medicine / University of Nineveh.
} 


\section{MATERIALS AND METHOD}

A descriptive design carried throughout the period 2nd of December 2013 - to March 2 nd 2014, in order to achieve its objectives of assessment of nursing staff knowledge and practice regarding care of premature babies in Mosul hospitals in the (Premature babies units) in AL-Batool ,AL-Mosul General, AL-Khansaa and AL-Salam Teaching Hospitals .employing quantitative research methods to attain the results. The sample of the study was a nonprobability purposive sampling which included all the nurses working in the premature units in these four Hospitals the sample consisted of (60) nurses (females).

A special questionnaire tool was constructed and designed by the researcher and the supervisor based on the review of literature. This questionnaire has 3 subscales used to measure demographic information, nursing knowledge, nursing practice in nursing care for premature babies.

The validity of the study was determined by exposing the content of the tool to a group of 23 specialized experts in different fields of sciences. A pilot study for the tool was done on 10 nurses who were working in AL-Mosul General Teaching Hospital from the period between 10th of January 2014 -to- 30th of January 2014, via filling a test-retest questionnaire on the same sample within this period.

The reliability of the study tool was determined by using Pearson's Coefficient Correlation, and the outcomes of the reliability coefficient (r.) was measured and the edit was( $r$ $=0.83, \mathrm{P}<0.002$ ) for the knowledge and practice fields respectively. The data were analyzed using the statistical package for social science (SPSS) program version 17 throughout the application of descriptive statistic (frequency, mean, standard deviation, and percentage) and inferential statistics (t-test and ANOVA-one way test).

\section{RESULTS}

(4-A) Characteristics of the sample:

Table (4-1): Socio-Demographical

Characteristics of the sample: $(\mathrm{N}=60)$.

\begin{tabular}{||l|c|c||}
\hline Variable & No. & $\%$ \\
\hline (A)Gender & $\mathbf{6 0}$ & $\mathbf{1 0 0 \%}$ \\
\hline Female & 60 & $\mathbf{1 0 0 \%}$ \\
\hline Total & \multicolumn{2}{|c|}{} \\
\hline (B)Age & $\mathbf{3 4}$ & $\mathbf{5 7}$ \\
\hline 20-29 years
\end{tabular}

\begin{tabular}{|c|c|c|}
\hline 30-39 years & 17 & 28 \\
\hline 40-49 years & 4 & 7 \\
\hline 50-59 years & 5 & 8 \\
\hline Total & 60 & $100 \%$ \\
\hline \multicolumn{3}{|l|}{ (C)Educational level } \\
\hline $\begin{array}{l}\text { Primary Nursing school } \\
\text { graduate }\end{array}$ & 1 & 2 \\
\hline $\begin{array}{l}\text { Secondary Nursing } \\
\text { school graduate }\end{array}$ & 31 & 52 \\
\hline Diploma in Nursing & 10 & 17 \\
\hline Baccalaureate in Nursing & 18 & 30 \\
\hline Total & 60 & $100 \%$ \\
\hline \multicolumn{3}{|c|}{ (D)Duration of nursing experience } \\
\hline $1-5$ years & 45 & 75 \\
\hline 6-10 years & 6 & $\mathbf{1 0}$ \\
\hline 11-15 years & 2 & 3 \\
\hline $16-20$ years & 1 & 2 \\
\hline 21-25 years & 2 & 3 \\
\hline 26-30 years & 4 & 7 \\
\hline Total & 60 & $100 \%$ \\
\hline \multicolumn{3}{|c|}{$\begin{array}{l}\text { Duration of nursing experience in } \\
\text { premature units }\end{array}$} \\
\hline 1-5 years & 47 & 78 \\
\hline 6-10 years & 5 & 8 \\
\hline 11-15 years & 2 & 3 \\
\hline 16-20 years & 2 & 3 \\
\hline 21-25 years & 2 & 3 \\
\hline 26- 30 years & 2 & 3 \\
\hline Total & 60 & $100 \%$ \\
\hline \multicolumn{3}{|c|}{ (E)Specialized training courses } \\
\hline Never & 25 & 42 \\
\hline Yes & 35 & 58 \\
\hline Total & 60 & $100 \%$ \\
\hline \multicolumn{3}{|l|}{$\begin{array}{l}\text { If answer training } \\
\text { courses yes:- }\end{array}$} \\
\hline \multicolumn{3}{|l|}{ Training places } \\
\hline In country & 32 & 91 \\
\hline Abroad & 3 & 9 \\
\hline Total & 35 & $100 \%$ \\
\hline \multicolumn{3}{|l|}{ (F)Hospital } \\
\hline AL-Batool & 24 & $40 \%$ \\
\hline AL-kansaa & 25 & $42 \%$ \\
\hline AL-Mosul General & 1 & $2 \%$ \\
\hline AL- Salam & 10 & $17 \%$ \\
\hline Total & 60 & $100 \%$ \\
\hline
\end{tabular}


(4-B) Aims attainment:

(4-B-1) Assessment of nurses' knowledge regarding care of Premature Babies :

Table: (4-2 )Total nurses' knowledge by using one sample T. test.

\begin{tabular}{|c|c|c|c|c|c|c|}
\hline No. & Mean & Test Value & SD & T cal. & T tab. & P value \\
\hline $\mathbf{6 0}$ & $\mathbf{2 0 . 6 1 6 7}$ & 15 & 2.22537 & 19.550 & 2.001 & $\mathbf{0 . 0 0 0} * *$ \\
\hline df $=\mathbf{( 5 9 )}, \boldsymbol{\alpha}=\mathbf{( 0 . 0 5 )}$ & \multicolumn{5}{|l}{} \\
\hline
\end{tabular}

(4-B-2) Assessment of nurses' practice regarding care of Premature Babies :

Table:( 4-3)Total nurses' practice by using one sample T. test.

\begin{tabular}{||l|l|l|c|c|c|c|}
\hline \multicolumn{1}{|c|}{ No. } & Mean & Test Value & SD & T cal. & T tab. & P value \\
\hline 60 & 22.9667 & 20 & 4.94706 & 4.645 & 2.001 & $0.000 * *$ \\
\hline df $=(59), \alpha=(0.05)$ & \multicolumn{4}{|l}{} \\
\hline
\end{tabular}

\section{DISCUSSION}

(60) nurses participated in the study. All participants $(100 \%)$ were females. More than half of the participants $(57 \%)$ were younger than 30 years old and had secondary nursing school education. As for general nursing work experience, about three quarters of the sampled students $(75 \%)$ had less than five years of work experience. More than forty of the participants (78\%) had less than five years of nursing experience in premature units and more than half of the sample $(58 \%)$ attended Pediatric nursing care training, most of these courses were in Iraq $(91 \%)$.However, majority $(57 \%)$ of participants stated that they acquired their premature nursing care from both school curriculum and work experience.

\section{(5.B) Aims attainment:}

(5.B.1) Discussion of nurses' knowledge about hypoglycemia (Table 4-2,3).

Total nurses' knowledge by using one sample T. test (4-2)

this study explores the level of knowledge and practice in nurses in premature babies units. Results of the study indicate that the nurses' knowledge, nurses seem to have adequate knowledge and practices to take care of premature babies. These results indicate that the nurses have no gap between knowledge and the practice to provide nursing care for premature babies. This can be explained by the fact that nurses working in neonate units gain more knowledge and experience while working in this unit by reading related literature and learning from colleges. . Experiential knowledge can explain adequate nursing practice in this study. Experiential knowledge is a kind of nursing knowledge that usually gained through observations during regular Practice as a nurse and from observing other nursing colleagues (Carole et al., 2005).
Level of knowledge, practice and Age:

This study found that level of knowledge varies significantly by nurse age specifically nurses between 40-49 years old had the highest level of knowledge. These findings were contradicted by the study findings of (Gomes, 2010) who assessed the knowledge of Intensive Care nurses on evidence based guidelines for prevention of ventilator pneumonia and he concluded that there was no correlation between nurses' age and their knowledge on the evidence based guidelines for prevention of pneumonia. However, our finding may be due to that older nurses have more clinical experience and have being exposed to a variety of clinical cases and scenarios which is likely to have increased their breadth and depth of knowledge. Also, this finding is supported by a study conducted in 318 European intensive care units and found that length of years in ICU practice increase nurses knowledge (Paul Fulbrook, John W., 2012).

\section{CONCLUSION}

On the bases of the objectives of the current study and outcomes of data analysis, the following have been concluded: Our results highlighted several important aspects of nurse's role in hospitals. Most of premature baby unit nursing staffs are female, young nurses who graduated from secondary nursing schools. Level of Knowledge was positively associated with level of practice

$(\mathrm{r}=0.39, \mathrm{p}<0.01)$ indicating that premature baby unit nurses who have more knowledge about neonatal care provide better nursing care leading to positive patient outcome. So, having adequate knowledge leads to adequate and better practices to take care of premature babies. Finely, there are significant differences between knowledge and practice of nursing staff about nursing care for premature babies with regard to age, level of education, 
and duration of work. Having diploma degree, being 40-49 years old, and more clinical experience in premature babies units increase neonatal nursing knowledge and practices.

*Level of knowledge, practice, and education level:

Our results indicate that participants with nursing diploma had higher Level of Knowledge compared to secondary nursing degree participants and baccalaureate in nursing participants .This indicates that there is an appropriate level of knowledge among nurses which leads to the fact that the higher educational level of nurses affects the application of information practically in a positive way. This result is in agreement with the result of (Elsayed L. et al., 2013). It was found that more than half of the nurses had diplomas and nearly one third of them had a bachelor's degree.

\section{RECOMMENDATION}

Based on the results of the study, the researcher recommends the following:

Nurses should update their knowledge and practice through training courses and training programs for nursing care for premature baby in order to improve their skills .Standardized nursing procedures and guidelines should be available to guide the nurses in dealing with high risk premature babies in the premature babies units and( NICUs).Nursing programs must be updated so that nurses can perform efficiently in modern hospitals. Establishing specialized centers for providing advanced medical and scientific care for premature babies. And Performing statistics by ministry of health of Iraq on the number of premature births in the country in order to reduce this phenomenon and finding appropriate solutions to the problems.

\section{REFERENCES}

Al- Maini, S.H.K. (2003). Knowledge and Practices of mother to word premature baby care. Unpublished Thesis, Baghdad University. P.p.1-5

BIencowe, H.; Cousens, S.; Oestergaared, MZ.; Moller, AB.; Rohde, S.; and Lawn JE. (2012).National, regional, and worldwide estimates of preterm birth rates in the year 2010 with the time trends since 1990 for selected countries. P.p.2162-21720.

Carole, A.; Estabrooks, William Rutakumwa; Merry Jo Levers; and Shannon Scott. (2005). Findlay sources of practice knowledge among nurse. Qual Health Res. P.p. 460-476.

ELsayed, L.A.; Nahed Said EL- Nagger, Sahar Mohamed Aly. (2013). Nursing care provided for neonates with respiratory distress syndrome in the intensive care units at Makkah Al- Mukarramah in Saudi Arabia . Life Sci J 2013. P.p,.34033412 http:// www.lifesciencesite.com.

Iacovidou, N.; Varsami, M.; and Syggellou, A. (2010). Neonatal outcome of preterm delivery. Ann N Y Acad SCI. P.p.130134.

Lawn, J.E.; Cousens, S.; Zupan, J.; Lancet Neonatal survival steering, T. (2005). 4million neonatal deaths. P.p. 891-900.

Paul Fulbrook; John W.; Albarran, Birte Baktoft; and Ben Sidebottom. (2012). A survey of European intensive care nurses, knowledge level. international Jounal of nursing studies. 49(2). P.p.191-200.

World Health Organization (WHO). (2007). Pocket book of hospital care for children : Guidelines of the management of common illnesses with limited resources. Geneva. 